\title{
20 Sexual minorities and the Olympics
}

\author{
Maki Hirayama
}

The 2020 Olympics and Paralympics are poised to have a significant impact on how Japanese society treats sexual minorities. Since Russia's well-known discrimination against gay people at the 2014 Sochi Winter Olympics provoked worldwide criticism, the Olympics and Paralympics have been opportunities to advocate for sexual minorities.

The Japanese Olympic Committee (JOC) declared "diversity and harmony" the theme of the Tokyo 2020 Games, encouraging various actors to work to reform society. In 2017, the JOC established the "Sourcing Code" for all direct and indirect suppliers, which prohibits discrimination due to gender, sexual orientation, and sexual identity and promotes respect for the rights of sexual minorities. Given the huge number of companies involved, the code's potential impact is significant.

The establishment of "Pride House Tokyo" in September 2018 is another major step for sexual minorities. The Pride House, a center for information and communication for sexual minorities, was first established by a voluntary group at the 2010 Vancouver Winter Olympics. Aided by international networking, similar Houses have been established in subsequent Olympics and Paralympics and other sports mega-events. The baton has now passed to Tokyo, where the House will be jointly managed by support groups before, during, and after the Games, and a permanent LGBT facility is planned as a legacy.

There are also promising legal developments. In October 2018, Tokyo became the first municipality to enact a human rights ordinance that included a sexual-minority discrimination ban. Yet same-sex marriage remains unrecognized. In February 2019, 13 same-sex couples filed a lawsuit against Japan for not recognizing same-sex marriage. One plaintiff, Oe Chizuka, remarked: "It's a good time to launch legal action because Japan is going to be the host country, and in the Olympic Charter discrimination due to sexual orientation is prohibited." Indeed, some members of parliament are moving to establish legislation guaranteeing equal rights for sexual minorities by 2020 . Whether this will change after 2020 remains to be seen. 